\title{
Research on a Micro-Nano Si/SiGe/Si Double Heterojunction Electro-Optic Modulation Structure
}

\author{
Song Feng $\mathbb{D}^{1},{ }^{1,2}$ Lian-bi Li $\left(\mathbb{D},{ }^{1}\right.$ and Bin Xue ${ }^{1}$ \\ ${ }^{1}$ School of Science, Xi'an Polytechnic University, Xian 710048, China \\ ${ }^{2}$ State Key Laboratory of Functional Materials for Informatics, Shanghai Institute of Microsystem and Information Technology, \\ Chinese Academy of Sciences, 865 Changning Road, Shanghai 200050, China \\ Correspondence should be addressed to Lian-bi Li; xpu_lilianbi@163.com
}

Received 26 October 2017; Accepted 20 March 2018; Published 2 May 2018

Academic Editor: Zaiquan Xu

Copyright (C) 2018 Song Feng et al. This is an open access article distributed under the Creative Commons Attribution License, which permits unrestricted use, distribution, and reproduction in any medium, provided the original work is properly cited.

\begin{abstract}
The electro-optic modulator is a very important device in silicon photonics, which is responsible for the conversion of optical signals and electrical signals. For the electro-optic modulator, the carrier density of waveguide region is one of the key parameters. The traditional method of increasing carrier density is to increase the external modulation voltage, but this way will increase the modulation loss and also is not conducive to photonics integration. This paper presents a micro-nano $\mathrm{Si} / \mathrm{SiGe} / \mathrm{Si}$ double heterojunction electro-optic modulation structure. Based on the band theory of single heterojunction, the barrier heights are quantitatively calculated, and the carrier concentrations of heterojunction barrier are analyzed. The band and carrier injection characteristics of the double heterostructure structure are simulated, respectively, and the correctness of the theoretical analysis is demonstrated. The micro-nano $\mathrm{Si} / \mathrm{SiGe} / \mathrm{Si}$ double heterojunction electro-optic modulation is designed and tested, and comparison of testing results between the micro-nano $\mathrm{Si} / \mathrm{SiGe} / \mathrm{Si}$ double heterojunction micro-ring electro-optic modulation and the micronano Silicon-On-Insulator (SOI) micro-ring electro-optic modulation, Free Spectrum Range, $3 \mathrm{~dB}$ Bandwidth, $Q$ value, extinction ratio, and other parameters of the micro-nano $\mathrm{Si} / \mathrm{SiGe} / \mathrm{Si}$ double heterojunction micro-ring electro-optic modulation are better than others, and the modulation voltage and the modulation loss are lower.
\end{abstract}

\section{Introduction}

With the rapid development of optoelectronic technology, optoelectronic devices have entered the nano era $[1,2]$, and many nanotechnology has been used in silicon photonics [35]. The reduced size of the device can improve the utilization rate of the chip area, but also the higher performance of the device is required, and the silicon epitaxial material is selected to make optoelectronic devices with higher performance. For example, the epitaxial InP material on silicon substrate is used to fabricate laser [6], the epitaxial Ge material is used to make detector [7], the epitaxial SiGe material is used to fabricate modulator [8], and so forth. In optoelectronic integration, the electro-optic modulator is a very important device, which is responsible for the conversion of optical signals and electrical signals $[9,10]$. For the electro-optic modulator, the carrier density of waveguide region is one of the key parameters. When the injected carrier density of waveguide region is greater, the change of refractive index is greater, and also the modulator is more easily modulated $[11,12]$. The traditional method of increasing carrier density is to increase the external modulation voltage, but this way will increase the modulation loss and also is not conducive to photonics integration $[8,13]$. So SiGe technology is one way to solve this problem in silicon photonics. Photonics Electronics Technology Research Association (PETRA) and University of Tokyo have made a high-speed and highly efficient Si optical modulator with strained SiGe layer and demonstrated highly efficient modulations of 0.67 and $0.81 \mathrm{~V} \cdot \mathrm{cm}$ for $\mathrm{V} \pi \mathrm{L}$ at $\mathrm{dc}$ reverse bias voltages of -0.5 and $-2 \mathrm{~V}_{\mathrm{dc}}$, respectively, and also demonstrated a high-speed operation of $25 \mathrm{Gbps}$ for the SiMOD at a wavelength of around $1.3 \mu \mathrm{m}$ [14]. University of Toronto has made SiGe BiCMOS linear modulator drivers, and the measured differential gain and bandwidth are over $20 \mathrm{~dB}$ and $70 \mathrm{GHz}$, respectively, and $\mathrm{P}_{1 \mathrm{~dB}}$ is $-2.5 \mathrm{dBm}$ [15]. Ghent University demonstrated single-wavelength, serial 


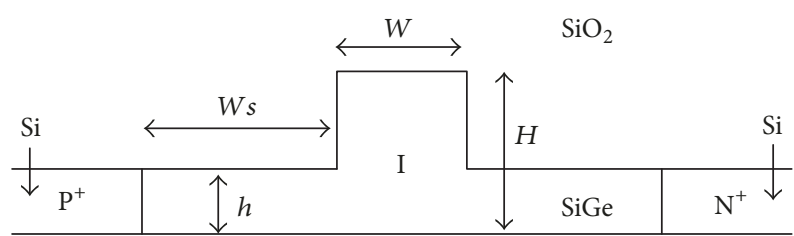

$\mathrm{SiO}_{2}$

$\mathrm{Si}$

Figure 1: Si/SiGe/Si-OI structure.

and real-time $100 \mathrm{~GB} / \mathrm{s}$ NRZ-OOK transmission over $500 \mathrm{~m}$ SSMF with a GeSi EAM implemented on a silicon photonics platform. The device was driven with $2 \mathrm{Vpp}$ without $50 \Omega$ termination, allowing a low-complexity solution for $400 \mathrm{GbE}$ short-reach optical interconnects [16].

This paper presents a micro-nano $\mathrm{Si} / \mathrm{SiGe} / \mathrm{Si}$ double heterojunction electro-optic modulation structure, which can greatly improve the carrier injection concentration and decrease modulation voltage and loss. It is an ideal electrooptic modulator, which is conducive to the photonics integrated circuit miniaturization and integration and also provides a new way for the research of micro-nano optoelectronic devices based on silicon.

\section{Structure and Energy Band}

Based on the SOI PIN electro-optic modulation structure, a micro-nano $\mathrm{Si} / \mathrm{SiGe} / \mathrm{Si}$ double heterojunction electro-optic modulation structure is presented, which is abbreviated as Silicon/Silicon Germanium/Silicon-On-Insulator (Si/SiGe/ $\mathrm{Si}$-OI) structure, as shown in Figure 1. The bottom of the structure is On-Insulator (OI) material, the $\mathrm{P}+$ and $\mathrm{N}+$ regions in the top layer are silicon materials, and the I region is SiGe material in Figure 1. P+region is doped by B element, and the doping concentration is $1 \times 10^{19} \mathrm{~cm}^{-3}$. N+ region is doped by $\mathrm{P}$ element, and the doping concentration is also $1 \times$ $10^{19} \mathrm{~cm}^{-3}$. I region is $\mathrm{N}$ type intrinsic $\mathrm{SiGe}$, and the doping concentration is $1 \times 10^{15} \mathrm{~cm}^{-3}$. In Figure 1, structure parameters are $H=220 \mathrm{~nm}, h=50 \mathrm{~nm}, W=400 \sim 600 \mathrm{~nm}$, and the width between active region and waveguide $(W s)$ is a variable value.

In order to facilitate comparison and analysis, two kinds of PIN modulation structures with $\mathrm{Si}$ and SiGe materials are established. One is the PIN modulation structure with Si based on the SOI PIN structure, which is abbreviated as SOI structure, as shown in Figure 2(a). The other is the PIN modulation structure with SiGe based on the Silicon Germanium-On-Insulator (SiGe-OI) PIN structure, which is abbreviated as SiGe-OI structure, as shown in Figure 2(b). The doping concentration and structure parameters of two structures are the same as $\mathrm{Si} / \mathrm{SiGe} / \mathrm{Si}$ double heterojunction electro-optic modulation structure.

$\mathrm{Si} / \mathrm{SiGe} / \mathrm{Si}$-OI structure is composed of $\mathrm{P}$ type $\mathrm{Si}$ with the high doping concentration, $\mathrm{N}$ type SiGe with the low doping concentration, and $\mathrm{N}$ type $\mathrm{Si}$ with the high doping concentration. Capital P and N represent Wide Band Gap Semiconductor, and lowercase $\mathrm{n}$ represents Narrow Band Gap Semiconductor. So the PIN structure can be equivalent as a Pn heterojunction and a $\mathrm{nN}$ heterojunction structure, and the band diagram is shown in Figure 3 under the equilibrium state.

When the PIN structure is working, the main carriers of $\mathrm{n}$ region are composed of electron from the $\mathrm{P}$ region and hole from the $\mathrm{N}$ region, and the barrier height is a key parameter who can influence injection efficiency of electron and hole. After heterojunction band of $\mathrm{Si} / \mathrm{SiGe} / \mathrm{Si}$-OI structure is analyzed, the hole barrier height of Pn heterojunction of the Si/ $\mathrm{SiGe} / \mathrm{Si}$-OI structure is represented by the following formula [17]:

$$
-q V_{D}=-k_{0} T \ln \frac{n_{i(\mathrm{Si})} n_{i(\mathrm{SiGe})}}{N_{D} N_{A}}-\frac{0.73 x}{2},
$$

where $q V_{D}$ is the barrier height, $k_{0}$ is the Boltzmann constant, $T$ is the absolute temperature, $n_{i(\mathrm{Si})}$ is the intrinsic carrier concentration of silicon, $n_{i(\mathrm{SiGe})}$ is the intrinsic carrier concentration of Silicon Germanium, $N_{D}$ is the doping concentration of $\mathrm{n}$ region, $N_{A}$ is the doping concentration of $\mathrm{P}$ region, $x$ is the Ge content. Formula (1) indicates that the hole barrier height of Pn heterojunction is related to the doping concentration of $\mathrm{P}$ region and $\mathrm{n}$ region, the band gap of materials, the temperature, and the Ge content. When the temperature is constant, the lower the doping concentration of $\mathrm{P}$ region and $\mathrm{n}$ region, the lower the hole barrier height. The narrower the band gap, the higher the intrinsic carrier concentration, and the lower the hole barrier height. The bigger the Ge content, the lower the hole barrier height.

Assuming that $N_{A}=10^{19} \mathrm{~cm}^{-3}, N_{D}=10^{15} \mathrm{~cm}^{-3}$, and the Ge content is 0.2 , so the hole barrier height of Pn heterojunction can be calculated equal to $-q V_{D}=0.7 \mathrm{eV}$ at room temperature. For SOI structure and SiGe-OI structure, the Pn junction is homojunction, and the hole barrier height can be analyzed according to the following formula [17]:

$$
-q V_{D 1,2}=E_{\mathrm{FP}}-E_{\mathrm{Fn}}=-k T \ln \frac{n_{i}^{2}}{N_{D} N_{A}},
$$

where $E_{\mathrm{FP}}$ is the Fermi level of the $\mathrm{P}$ region and $E_{\mathrm{Fn}}$ is the Fermi level of the $\mathrm{n}$ region. The hole barrier height of Pn homojunctions of the SOI structure can be calculated equal to $-q V_{D 1}=0.82 \mathrm{eV}$, and the hole barrier height of Pn homojunctions of the SiGe-OI structure can be calculated equal to $-q V_{D 2}=0.733 \mathrm{eV}$. In the same conditions, the hole barrier height of the $\mathrm{Si} / \mathrm{SiGe} / \mathrm{Si}$-OI structure is lowest, and the hole barrier height of the SOI structure is highest. This result can be verified by Silvaco CAD software, as shown in Figure 4 [17].

The electron barrier height of $\mathrm{nN}$ heterojunction of the $\mathrm{Si} / \mathrm{SiGe} / \mathrm{Si}$-OI structure can be represented by the following formula [17]:

$$
q V_{D}^{\prime}=k T \ln \frac{N_{D}^{\prime} n_{i(\mathrm{SiGe})}}{N_{D} n_{i(\mathrm{Si})}}-\frac{0.73 x}{2},
$$

where $N_{D}^{\prime}$ is the carrier concentration of $\mathrm{N}$ region and $N_{D}$ is the carrier concentration of $\mathrm{n}$ region. Formula (3) indicates 


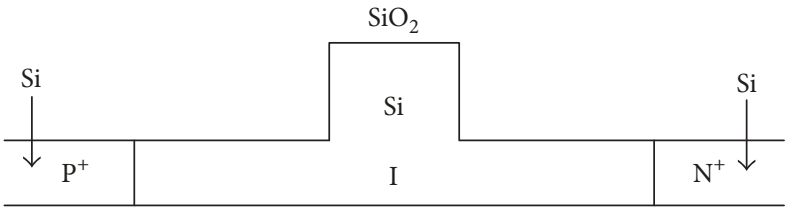

$\mathrm{SiO}_{2}$ $\mathrm{Si}$

(a)

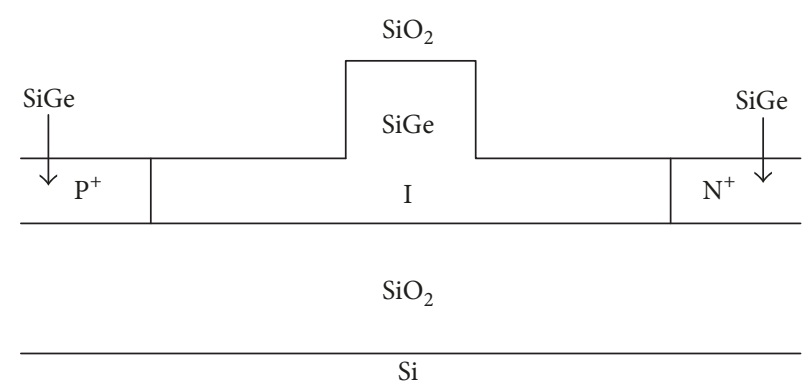

(b)

FIgURE 2: Two type modulation structures: (a) SOI structure and (b) SiGe-OI structure.

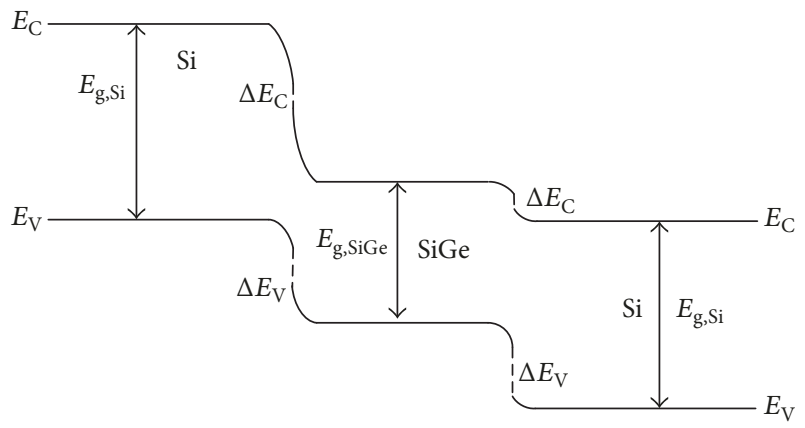

Figure 3: The band diagram of $\mathrm{Si} / \mathrm{SiGe} / \mathrm{Si}-\mathrm{OI}$ structure under the equilibrium state.

that the electron barrier height of the $\mathrm{nN}$ heterojunction of $\mathrm{Si} / \mathrm{SiGe} / \mathrm{Si}-\mathrm{OI}$ structure is also related to the doping concentration of $\mathrm{N}$ region and $\mathrm{n}$ region, the band gap of materials, the temperature, and the Ge content. When the temperature is constant, the lower the doping concentration of $\mathrm{N}$ region, the lower the hole barrier height. The higher the doping concentration of $\mathrm{n}$ region, the lower the hole barrier height. The wider band gap of $\mathrm{n}$ region, the lower the intrinsic carrier concentration, and the lower the hole barrier height. The narrower the band gap of $\mathrm{N}$ region, the higher the intrinsic carrier concentration, and the lower the hole barrier height. The smaller the Ge content, the lower the hole barrier height.

Assuming that $N_{D}^{\prime}=10^{19} \mathrm{~cm}^{-3}, N_{D}=10^{15} \mathrm{~cm}^{-3}$, and the Ge content is 0.2 , so the electron barrier height of $\mathrm{nN}$ heterojunction can be calculated equal to $q V_{D}^{\prime}=0.2 \mathrm{eV}$ at room temperature. For SOI structure and SiGe-OI structure, the $\mathrm{nN}$ junction is homojunction, and the electron barrier height can be analyzed according to the following formula [17]:

$$
q V_{D 1,2}^{\prime}=E_{\mathrm{FN}}-E_{\mathrm{Fn}}=k T \ln \frac{N_{D}^{\prime}}{N_{D}} .
$$

The electron barrier height of $\mathrm{nN}$ homojunctions of the SOI structure can be calculated equal to $q V_{D 1}^{\prime}=0.24 \mathrm{eV}$, and the electron barrier height of $\mathrm{nN}$ homojunctions of the SiGeOI structure can be calculated equal to $q V_{D 2}^{\prime}=0.24 \mathrm{eV}$. In the same conditions, the electron barrier height of the $\mathrm{Si} / \mathrm{SiGe} / \mathrm{Si}$ OI structure is lowest, and the electron barrier height of the
SOI structure is highest. This result can be verified by Silvaco CAD software, as shown in Figure 4.

When the forward bias voltage is set between $\mathrm{P}$ region and $\mathrm{N}$ region, the original balance between carrier diffusion motion and drift motion is broken, and the PIN device is under nonequilibrium state. Because the doping concentration of the I region is very small, the resistance is very large. The doping concentration of the $\mathrm{P}$ region and the $\mathrm{N}$ region is very large, and the resistance is very small, so the external positive bias voltage is basically born in the I region. The forward bias voltage produces an electric field opposite to the Built-in Electric Field in the I region, which weakens the intensity of the electric field in the I region and reduces the space charge, so the barrier height decreases. Because the hole barrier height of Pn heterojunction and the electron barrier height of $\mathrm{nN}$ heterojunction of $\mathrm{Si} / \mathrm{SiGe} / \mathrm{Si}-\mathrm{OI}$ structure all are lower than the barrier height of SiGe-OI structure and SOI structure, so the band of $\mathrm{Si} / \mathrm{SiGe} / \mathrm{Si}-\mathrm{OI}$ structure is flattened first under the forward bias voltage. In other words, the $\mathrm{Si} / \mathrm{SiGe} / \mathrm{Si}-\mathrm{OI}$ structure has the higher carrier injection at the same forward bias voltage. At $1 \mathrm{~V}$ forward voltage, the band simulations of three type modulation structures are shown in Figure 5 [17].

\section{Result Analysis}

In order to verify that the $\mathrm{Si} / \mathrm{SiGe} / \mathrm{Si}-\mathrm{OI}$ structure has better characteristics, the carrier concentration of the SOI structure, the $\mathrm{SiGe}-\mathrm{OI}$ structure, and the $\mathrm{Si} / \mathrm{SiGe} / \mathrm{Si}-\mathrm{OI}$ structure are shown in Figure 6. Figure 6(a) shows the relationship between the electron concentration and modulation voltage for three structures, and Figure 6(b) shows the relationship between the hole concentration and modulation voltage. It can be seen from Figure 6 that, with the increase of modulation voltage, the carrier concentration of three kinds of modulation structure all are gradually increased. When the modulation voltage exceeds $0.6 \mathrm{~V}$, the carrier concentration of the $\mathrm{Si} / \mathrm{SiGe} / \mathrm{Si}-\mathrm{OI}$ structure is significantly greater than the carrier concentration of the SOI structure; when the modulation voltage is greater than $0.75 \mathrm{~V}$, the carrier concentration of the $\mathrm{Si} / \mathrm{SiGe} / \mathrm{Si}$-OI structure is significantly greater than the carrier concentration of SiGe-OI structure; when the modulation voltage is up to $0.9 \mathrm{~V}$, the carrier concentration of the $\mathrm{Si} / \mathrm{SiGe} / \mathrm{Si}$-OI structure is $6 \times 10^{18} \mathrm{~cm}^{-3}$, but the SOI structure 


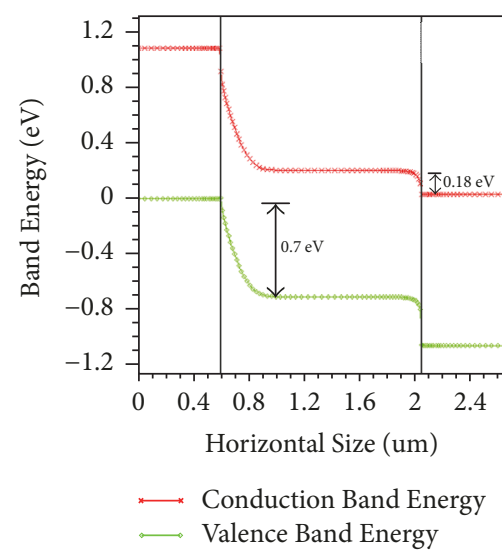

(a)

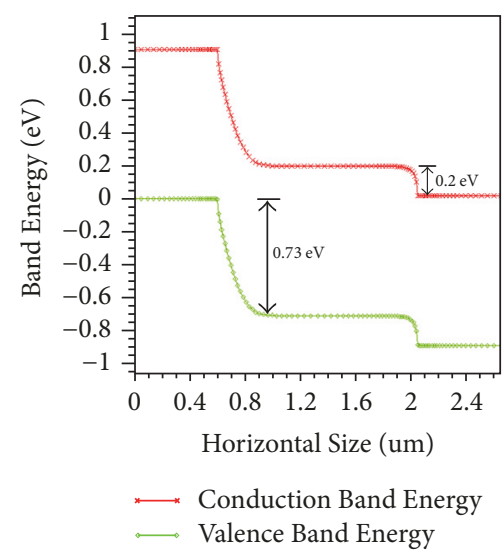

(b)

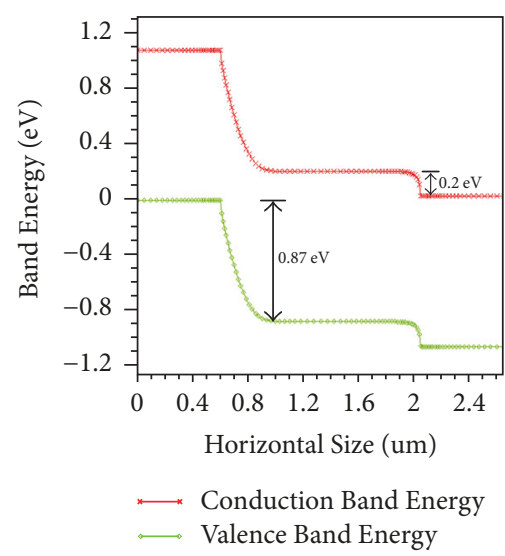

(c)

FIGURE 4: The band simulation of three type modulation structures: (a) Si/SiGe/Si-OI structure, (b) SiGe-OI structure, and (c) SOI structure.

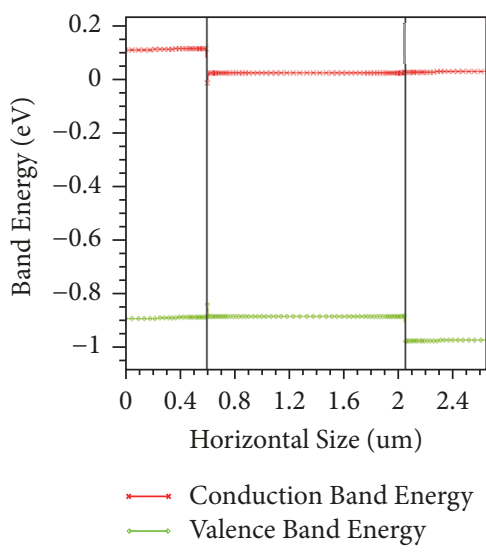

(a)

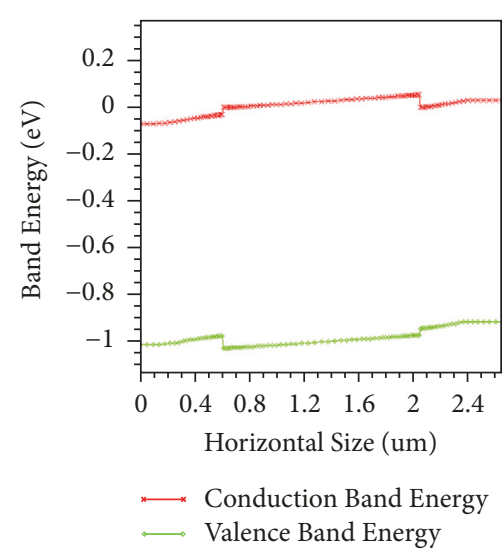

(b)

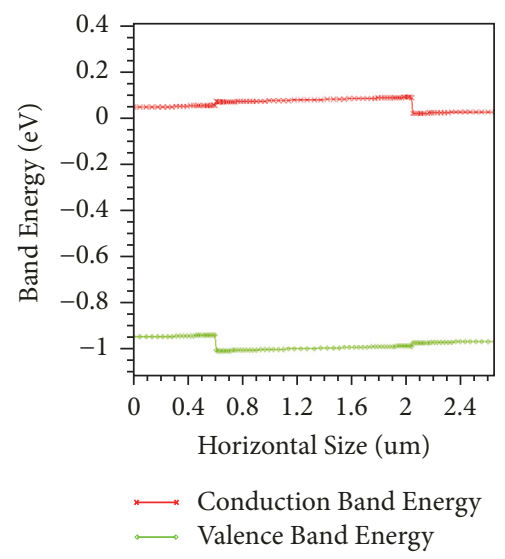

(c)

Figure 5: At $1 \mathrm{~V}$ forward voltage, the band simulation of three type modulation structures: (a) Si/SiGe/Si-OI structure, (b) SiGe-OI structure, and (c) SOI structure.

and the $\mathrm{SiGe}$-OI structure reach the same carrier concentration at $2 \mathrm{~V}$ modulation voltage; when the modulation voltage reaches $2 \mathrm{~V}$, the carrier concentration of the $\mathrm{Si} / \mathrm{SiGe} / \mathrm{Si}$-OI structure could increase to $1.5 \times 10^{19} \mathrm{~cm}^{-3}$. Assuming the SOI structure and the SiGe-OI structure all work at $2 \mathrm{~V}$ modulation voltage, so the $\mathrm{Si} / \mathrm{SiGe} / \mathrm{Si}$-OI structure can work only at $0.9 \mathrm{~V}$ modulation voltage. From that we can see the modulation voltage of electro-optic modulator effectively is reduced, and the injection efficiency of electro-optic modulator effectively is improved for the $\mathrm{Si} / \mathrm{SiGe} / \mathrm{Si}$-OI structure.

In order to verify the correctness of the theoretical analysis and simulation results, we have made the micro-nano $\mathrm{Si} / \mathrm{SiGe} / \mathrm{Si}$ double heterojunction electro-optic modulation, as shown in Figure 7. For the modulation of the optical part, the micro-ring modulation structure is selected. Figure 7(a) shows schematic diagram of the micro-nano $\mathrm{Si} / \mathrm{SiGe} / \mathrm{Si}$ double heterojunction micro-ring electro-optic modulation, Figure 7(b) shows Laser Scanning Confocal Microscopy (LSCM) picture of device by LEXT-OLS4000, Figure 7(c) shows Scanning Electron Microscope (SEM) picture of micro-ring structure by JSM-6700F, and Figure 7(d) shows SEM of device. The waveguide width is $450 \mathrm{~nm}$, the ridge waveguide height is $220 \mathrm{~nm}$, the planar waveguide height is $50 \mathrm{~nm}$, the gap between waveguide and micro-ring is $200 \mathrm{~nm}$, the micro-ring radius is $10 \mu \mathrm{m}$, the doping concentration of $\mathrm{P}+$ region is $1 \times 10^{19} \mathrm{~cm}^{-3}$, the doping concentration of $\mathrm{N}+$ region is $1 \times 10^{19} \mathrm{~cm}^{-3}$, and the doping concentration of I region is $1 \times 10^{15} \mathrm{~cm}^{-3}$. At the same processing conditions and device parameters, the micro-nano SOI micro-ring electrooptic modulation is also made for testing comparison.

The transmission spectrum of the micro-nano $\mathrm{Si} / \mathrm{SiGe} / \mathrm{Si}$ double heterojunction micro-ring electro-optic modulation has been tested, as shown in Figure 8. From that we can see the Free Spectrum Range (FSR) is $9.44 \mathrm{~nm}$, and the $3 \mathrm{~dB}$ Bandwidth of the resonant peak is $0.12 \mathrm{~nm}$, near the $1549 \mathrm{~nm}$. The corresponding $Q$ value is 12900 , and the extinction ratio of the resonant peak is $11.2 \mathrm{~dB}$.

At the same testing conditions, the transmission spectrum of the micro-nano SOI micro-ring electro-optic modulation has also been tested, as shown in Figure 9. From that 


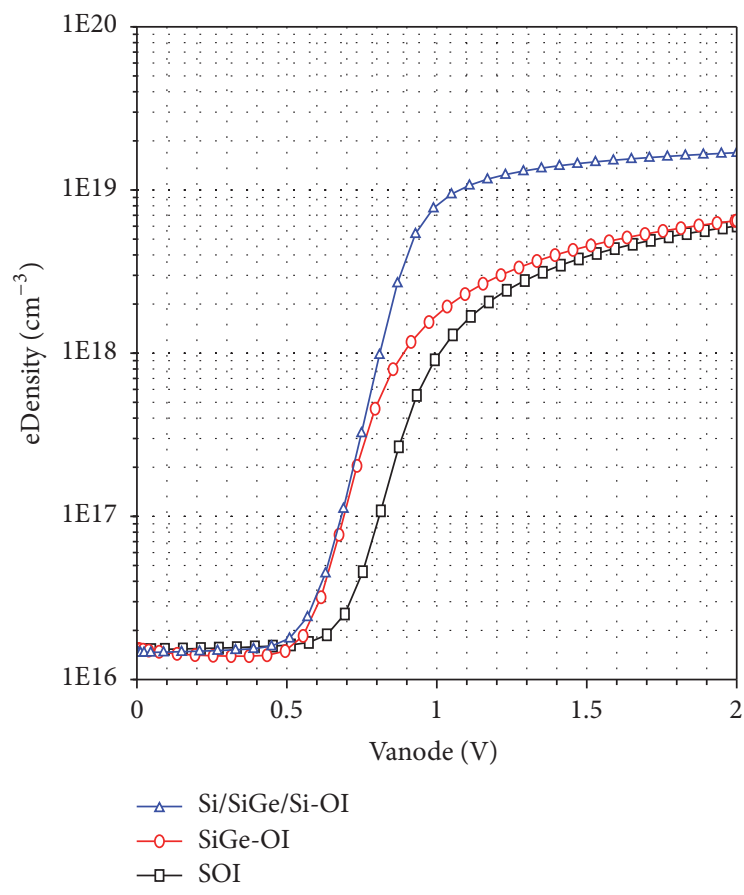

(a)

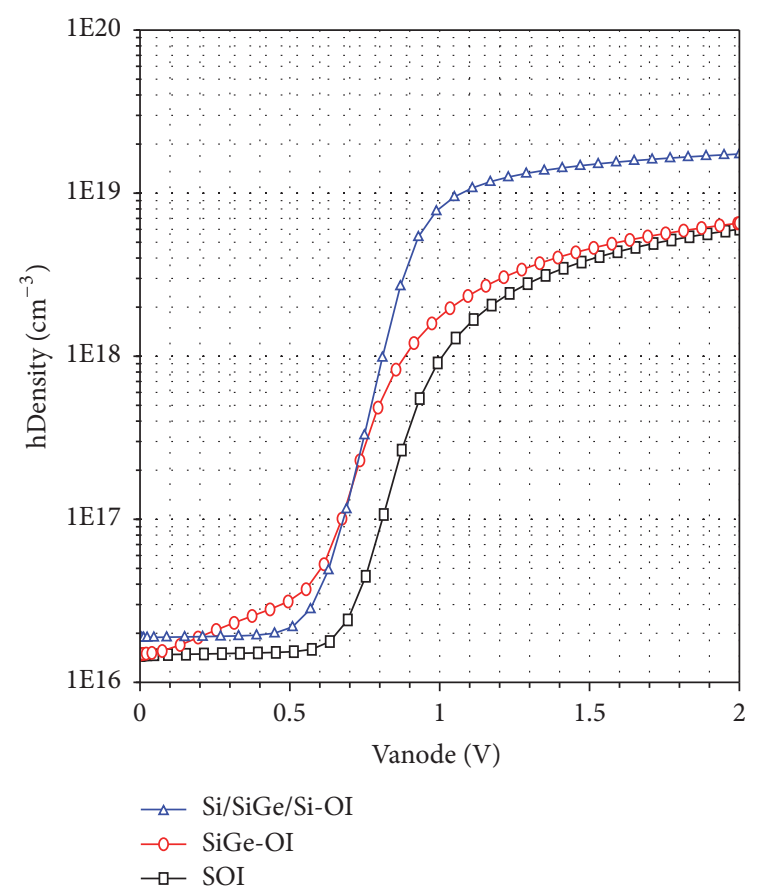

(b)

FIGURE 6: The relationship between the carriers concentration and modulation voltage: (a) electron concentration and (b) hole concentration for three structures.

we can see the Free Spectrum Range (FSR) is $9.41 \mathrm{~nm}$, and the $3 \mathrm{~dB}$ Bandwidth of the resonant peak is $0.13 \mathrm{~nm}$, near the $1548 \mathrm{~nm}$. The corresponding $Q$ value is 11900 , and the extinction ratio of the resonant peak is $7.0 \mathrm{~dB}$.

From the comparison of testing results between the micro-nano $\mathrm{Si} / \mathrm{SiGe} / \mathrm{Si}$ double heterojunction micro-ring electro-optic modulation and the micro-nano SOI micro-ring electro-optic modulation, we can see that Free Spectrum Range, $3 \mathrm{~dB}$ Bandwidth, $Q$ value, extinction ratio, and other parameters of the micro-nano $\mathrm{Si} / \mathrm{SiGe} / \mathrm{Si}$ double heterojunction micro-ring electro-optic modulation are better than that of the micro-nano SOI micro-ring electro-optic modulation, and $Q$ value and the extinction ratio are especially greater than that of the micro-nano SOI micro-ring electro-optic modulation.

The test result of the micro-nano $\mathrm{Si} / \mathrm{SiGe} / \mathrm{Si}$ double heterojunction micro-ring electro-optic modulation is shown in Figure 10. The forward bias voltages are $0,1,1.1,1.2 \mathrm{~V}$, respectively. From that we can see the resonant peak has obviously been blue-shifted after the forward bias voltage is set. When the forward bias voltage is $1 \mathrm{~V}$, the value of blue-shift is $0.71 \mathrm{~nm}$

When the forward bias voltages are $0,1.5,1.8,2 \mathrm{~V}$, respectively, the transmission spectrum of the micro-nano SOI micro-ring electro-optic modulation has been tested, as shown in Figure 11. From that we can see the resonant peak has also obviously been blue-shifted after the forward bias voltage is set, but the modulation effect is worse than $\mathrm{Si} / \mathrm{SiGe} / \mathrm{Si}$ modulation. Only when the forward bias voltage is up to $2 \mathrm{~V}$, the value of blue-shift is $0.71 \mathrm{~nm}$.
From the comparison of testing results between the micro-nano $\mathrm{Si} / \mathrm{SiGe} / \mathrm{Si}$ double heterojunction micro-ring electro-optic modulation and the micro-nano SOI microring electro-optic modulation, we can see that the modulation efficiency of the micro-nano $\mathrm{Si} / \mathrm{SiGe} / \mathrm{Si}$ double heterojunction micro-ring electro-optic modulation is better than that of the micro-nano SOI micro-ring electro-optic modulation at the same processing conditions and testing conditions. In other words, the modulation voltage of the micro-nano Si/$\mathrm{SiGe/Si}$ double heterojunction micro-ring electro-optic modulation is lower than that of the micro-nano SOI microring electro-optic modulation, and the modulation power of the micro-nano $\mathrm{Si} / \mathrm{SiGe} / \mathrm{Si}$ double heterojunction micro-ring electro-optic modulation is lower too. So the testing results are consistent with previous theoretical analysis and simulation results.

\section{Conclusions}

This paper presents a micro-nano $\mathrm{Si} / \mathrm{SiGe} / \mathrm{Si}$ double heterojunction electro-optic modulation structure. Based on the band theory of single heterojunction, the barrier height of the new structure is quantitatively analyzed, and the formulas of barrier height are gotten using the numerical calculus and derivation. The reason of carrier injection enhancement in the new structure is analyzed. On the simulation platform, the new structure, $\mathrm{SiGe}$-OI structure, and SOI structure are simulated. From the comparison of simulation results, when the modulation voltage is up to $0.9 \mathrm{~V}$, the carrier concentration of the new structure is $6 \times 10^{18} \mathrm{~cm}^{-3}$, but the SOI structure and 


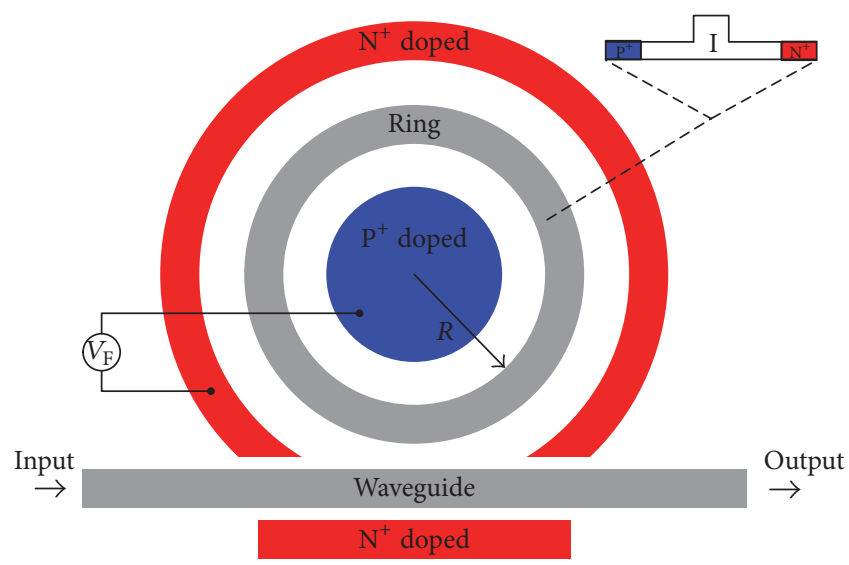

(a)

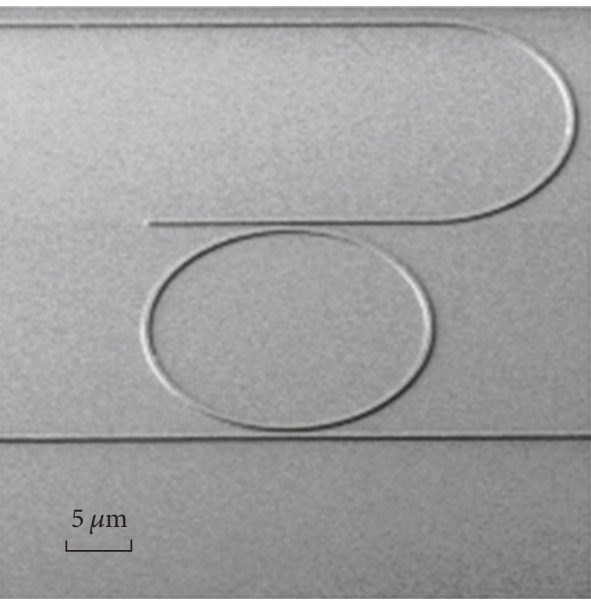

(c)

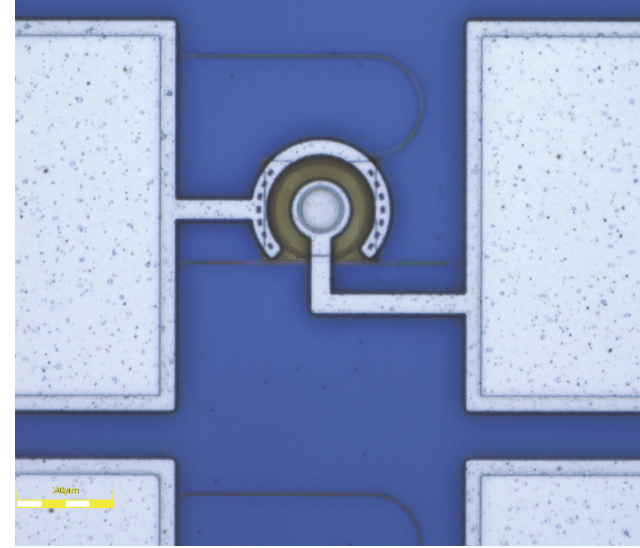

(b)

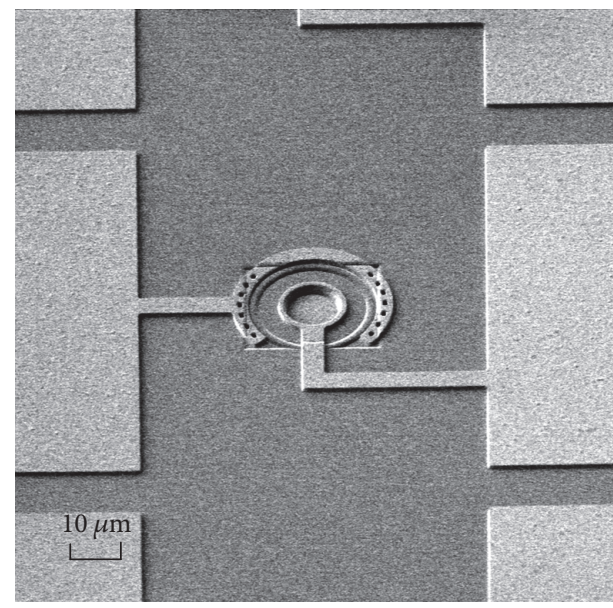

(d)

FIgURE 7: (a) Schematic diagram of device, (b) LSCM of device, (c) SEM of micro-ring structure, and (d) SEM of device.

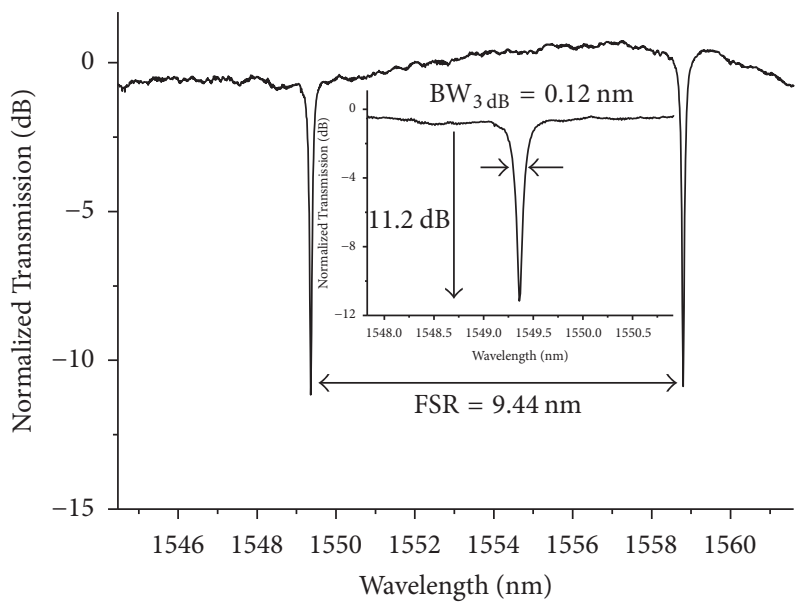

Figure 8: The transmission spectrum of the micro-nano $\mathrm{Si} / \mathrm{SiGe} / \mathrm{Si}$ double heterojunction micro-ring electro-optic modulation.

the $\mathrm{SiGe}-\mathrm{OI}$ structure reach the same carrier concentration at $2 \mathrm{~V}$ modulation voltage. Finally, the micro-nano $\mathrm{Si} / \mathrm{SiGe} / \mathrm{Si}$ double heterojunction electro-optic modulation is made and

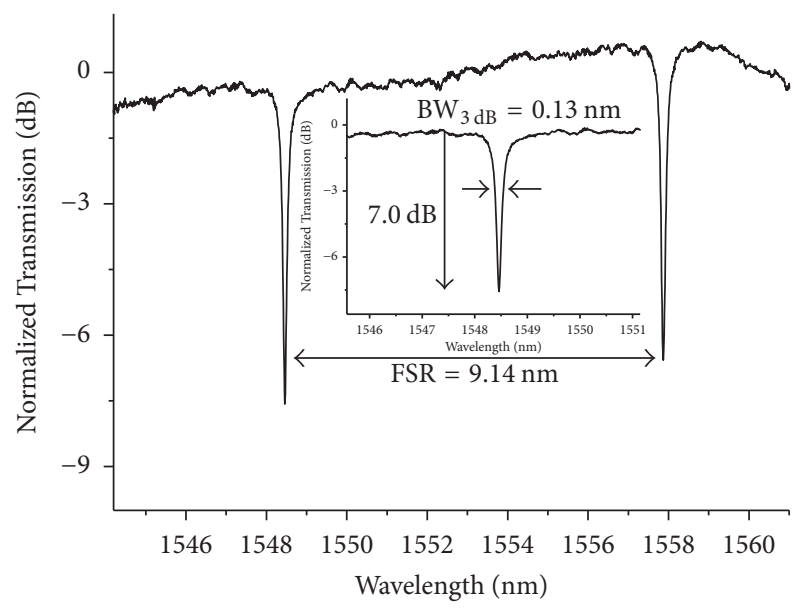

FIGURE 9: The transmission spectrum of the micro-nano SOI microring electro-optic modulation.

tested. Comparison of testing results between the micro-nano $\mathrm{Si} / \mathrm{SiGe} / \mathrm{Si}$ double heterojunction micro-ring electro-optic 


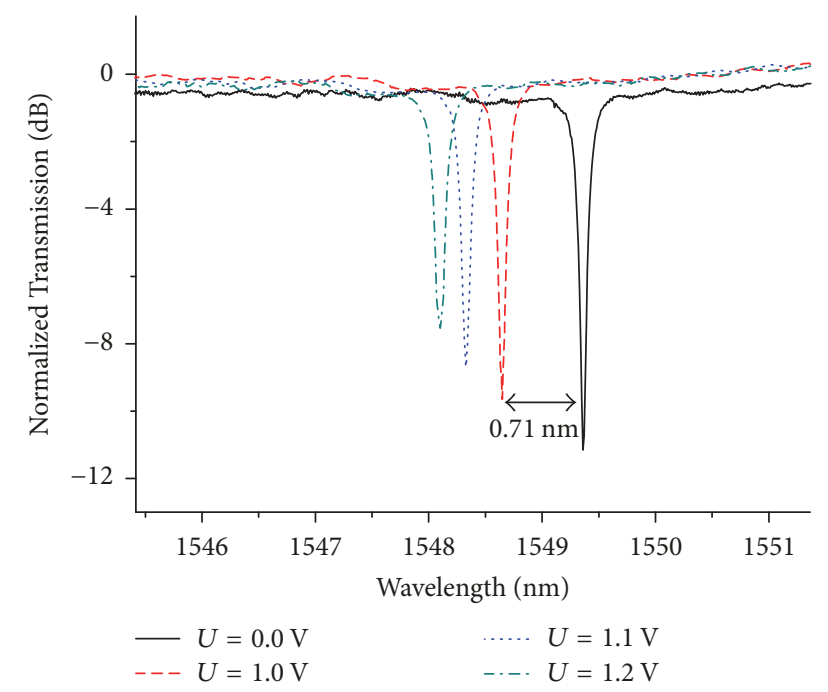

FIgURE 10: The static modulation of the micro-nano Si/SiGe/Si double heterojunction micro-ring electro-optic modulation.

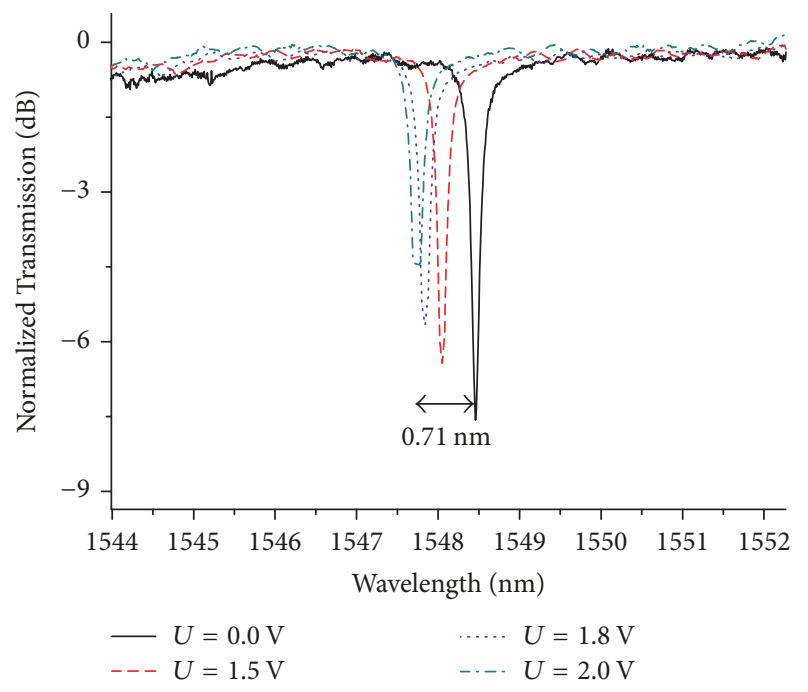

FIGURE 11: The static modulation of the micro-nano SOI micro-ring electro-optic modulation.

modulation and the micro-nano SOI micro-ring electrooptic modulation, Free Spectrum Range, 3 dB Bandwidth, $Q$ value, extinction ratio, and other parameters of the micronano $\mathrm{Si} / \mathrm{SiGe} / \mathrm{Si}$ double heterojunction micro-ring electrooptic modulation are better than others, and the modulation voltage and the modulation power are lower. So, the micronano $\mathrm{Si} / \mathrm{SiGe} / \mathrm{Si}$ double heterojunction electro-optic modulation structure is an ideal device structure to replace the traditional SOI and SiGe-OI electro-optic modulators structure.

\section{Conflicts of Interest}

The authors declare that they have no conflicts of interest.

\section{Acknowledgments}

This work was financially supported by National Natural Science Foundation of China (Grant no. 61204080), Natural Science Foundation of Shaanxi Province of China (Grant no. 2017JM6075), Foundation of Shaanxi Provincial Education Department (Grant no. 17JK0335), State Key Laboratory of Functional Materials for Informatics (Grant no. SKL201804), and Shaanxi Province Ordinary University Key Disciplines Construction Projects of Special Funds (Grant no. (2008)169).

\section{References}

[1] K. Singh and D. Kaur, "Vertically arrays of Si-LaNiO3/BiFeO3/ $\mathrm{Au}$ core-shell nano-capacitors for prominent coupled electrooptic effect," Journal of Applied Physics, vol. 121, no. 11, Article ID 114103, 2017.

[2] K. Nozaki, S. Matsuo, T. Fujii et al., "Photonic-crystal nanophotodetector with ultrasmall capacitance for on-chip light-tovoltage conversion without an amplifier," Optica, vol. 3, no. 5, pp. 483-492, 2016.

[3] Q. Fang, J. Song, X. Luo et al., "Low Loss Fiber-to-Waveguide Converter with a 3-D Functional Taper for Silicon Photonics," IEEE Photonics Technology Letters, vol. 28, no. 22, pp. 2533 2536, 2016.

[4] Z. Zhang, J. Hu, H. Chen et al., "Low-crosstalk silicon photonics arrayed waveguide grating," Chinese Optics Letters, vol. 15, no. 4, Article ID 041301, 2017.

[5] Q. Fang, J. Hu, Z. Zhang et al., "A ring-mirrors-integrated silicon photonics arrayed waveguide grating," in Proceedings of the 2017 Conference on Lasers and Electro-Optics Pacific Rim (CLEO-PR), pp. 1-2, Singapore, July 2017.

[6] J. Bowers, M. Davenport, and S. Liu, "A $20 \mathrm{GHz}$ colliding pulse mode-locked heterogeneous InP-silicon laser," Cleo: Science Innovations, vol. SW4C.5, 2017.

[7] W. Hua and S.-X. Liu, "Nonlinear resonance phenomenon of one-dimensional Bose - Einstein condensate under periodic modulation," Chinese Physics B, vol. 23, no. 2, Article ID 020309, 2014.

[8] S. Akiyama, M. Imai, T. Baba et al., "Compact PIN-diode-based silicon modulator using side-wall-grating waveguide," IEEE Journal of Selected Topics in Quantum Electronics, vol. 19, no. 6, pp. 74-84, 2013.

[9] H. Zwickel, S. Wolf, C. Kieninger et al., "Silicon-organic hybrid $(\mathrm{SOH})$ modulators for intensity-modulation / direct-detection links with line rates of up to $120 \mathrm{Gbit} / \mathrm{s,"}$ Optics Express, vol. 25, no. 20, pp. 23784-23800, 2017.

[10] S. Heidmann, G. Ulliac, N. Courjal, and G. Martin, "Characterization and control of the electro-optic phase dispersion in lithium niobate modulators for wide spectral band interferometry applications in the mid-infrared," Applied Optics, vol. 56, no. 14, pp. 4153-4157, 2017.

[11] N. Hoppe, C. Rothe, A. Celik et al., "Single waveguide siliconorganic hybrid modulator," Advances in Radio Science, vol. 15, pp. 141-147, 2017.

[12] M. Lauermann, S. Wolf, P. C. Schindler et al., "40 GBd 16QAM signaling at $160 \mathrm{~Gb} / \mathrm{s}$ in a silicon-organic hybrid modulator," Journal of Lightwave Technology, vol. 33, no. 6, Article ID 7015552, pp. 1210-1216, 2015. 
[13] M. Streshinsky, R. Ding, A. Novack et al., "50 Gb/s silicon traveling wave Mach-Zehnder modulator near $1300 \mathrm{~nm}$," in Proceedings of the Optical Fiber Communications Conference and Exhibition, vol. 14560428:1-3, 2014.

[14] J. Fujikata, M. Noguchi, Y. Kim et al., "High-speed and highly efficient Si optical modulator with strained SiGe layer," Applied Physics Express, vol. 11, no. 3, p. 032201, 2018.

[15] R. J. A. Baker, J. Hoffman, P. Schvan, and S. P. Voinigescu, "SiGe BiCMOS linear modulator drivers with 4.8-Vpp differential output swing for 120-GBaud applications," in Proceedings of the 2017 IEEE Radio Frequency Integrated Circuits Symposium, RFIC 2017, pp. 260-263, USA, June 2017.

[16] J. Verbist, M. Verplaetse, S. A. Srinivasan et al., "Real-Time 100 $\mathrm{Gb} / \mathrm{s}$ NRZ-OOK transmission with a silicon photonics GeSi electro-Absorption modulator," in Proceedings of the 6th IEEE Photonics Society Optical Interconnects Conference, OI 2017, pp. 29-30, USA, June 2017.

[17] S. Feng, B. Xue, LB. Li et al., "Analysis of Si/SiGe/Si double heterojunction band about a noval structure of PIN electronic modulation," Acta Physica Sinica, vol. 65, no. 5, article 054201, Article ID 054201, 2016. 

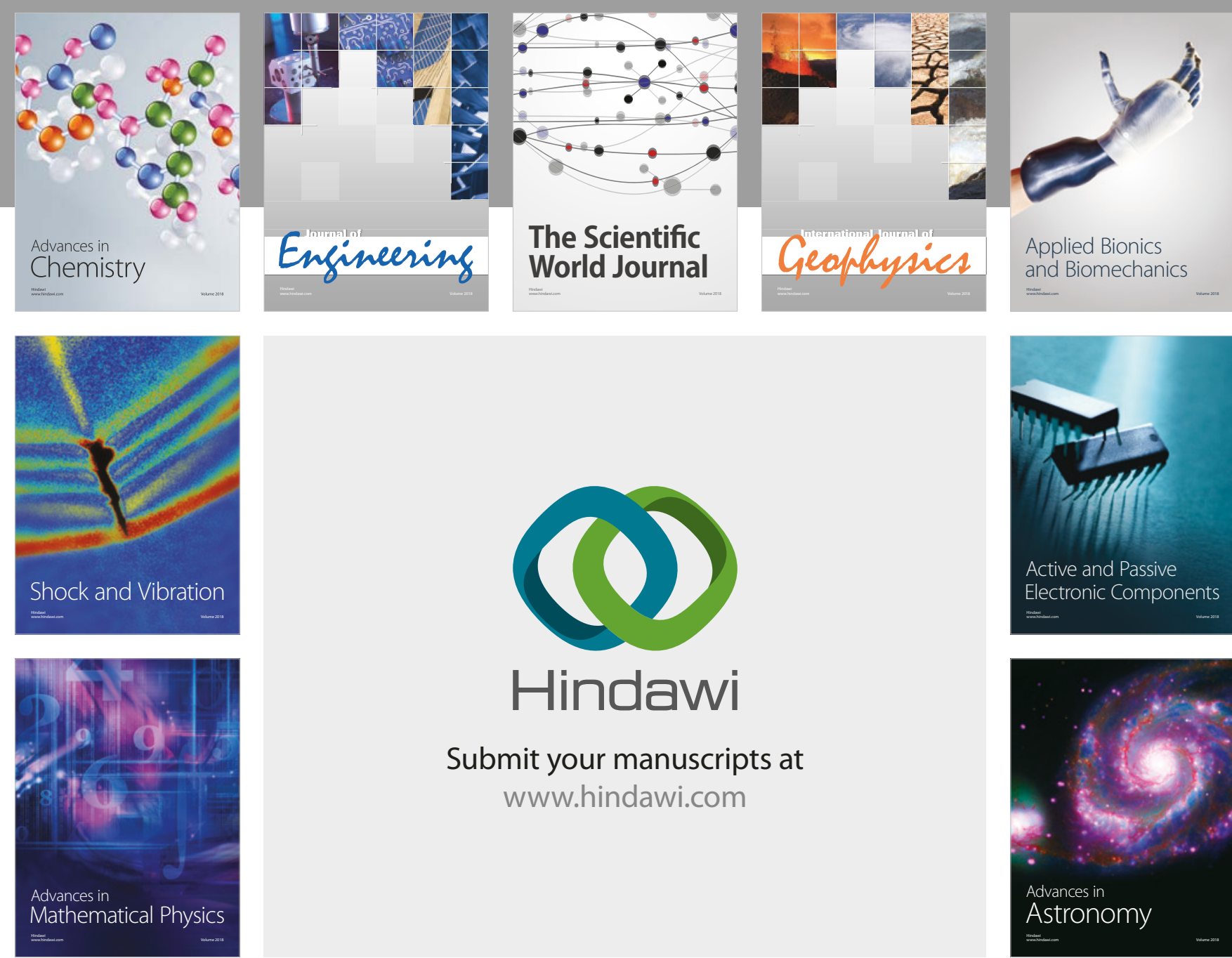

Submit your manuscripts at

www.hindawi.com

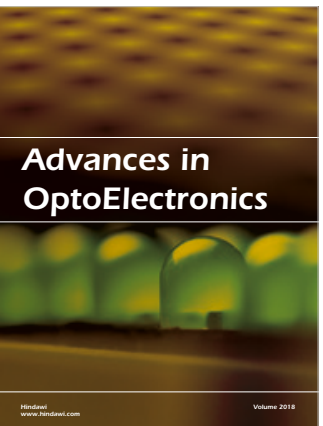

\section{Rotcting Machinery}
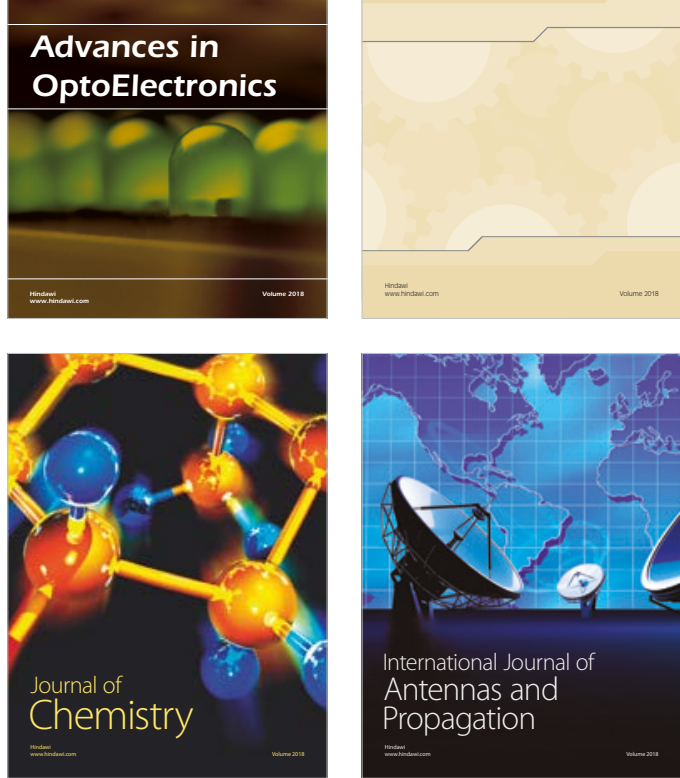

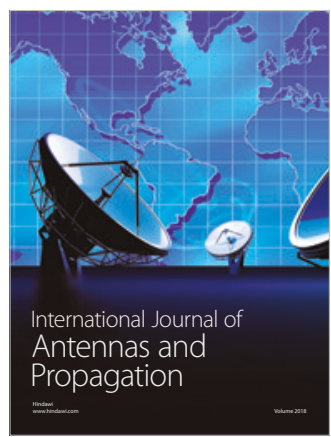

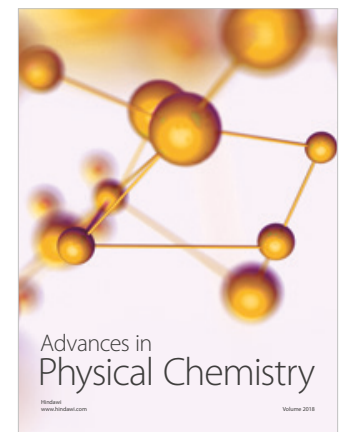

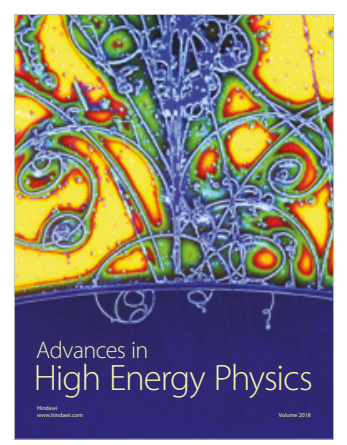

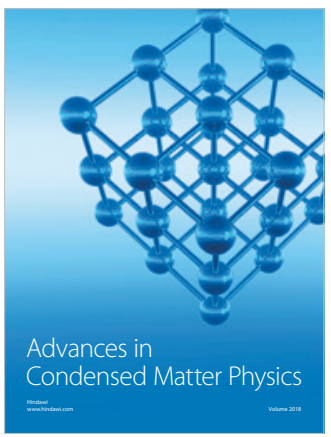

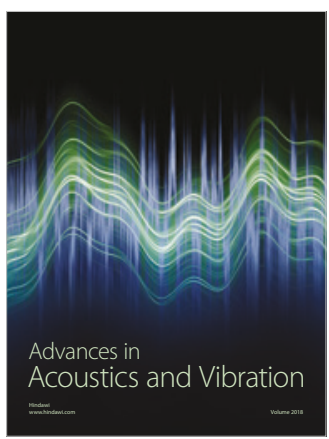

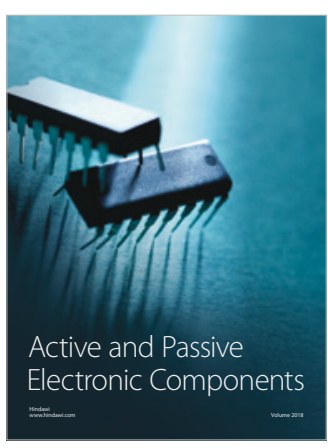
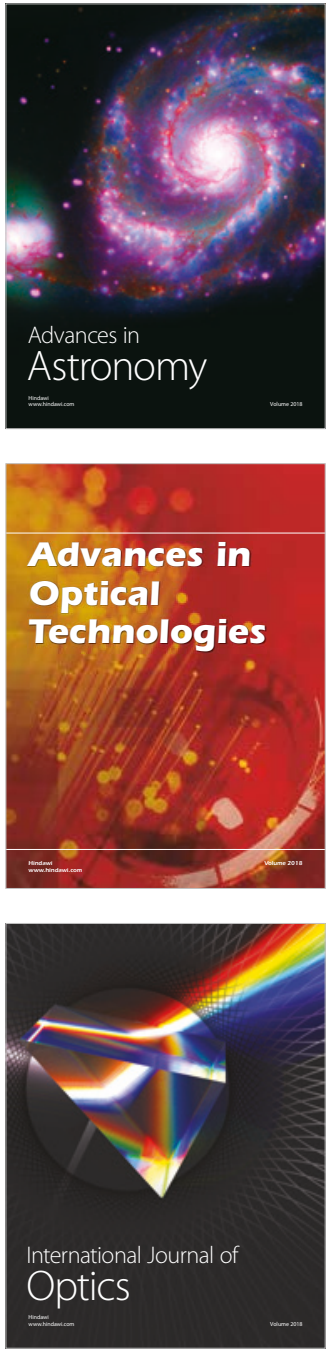